\title{
The role of AIB1 in breast cancer (Review)
}

\author{
ALAN K. CHANG and HUIJIAN WU \\ College of Life Science and Biotechnology, Dalian University of Technology, Dalian, Liaoning 116024, P.R. China
}

Received March 27, 2012; Accepted July 2, 2012

DOI: $10.3892 / 01.2012 .803$

\begin{abstract}
Amplified in breast cancer 1 (AIB1) is a member of the p160 steroid receptor coactivator family that mediates the transcriptional activities of nuclear receptors including estrogen receptor (ER) and progesterone receptor (PR), as well as certain other transcription factors, including E2F1 and p53. AIB1 is widely implicated in nuclear receptor-mediated diseases, particularly malignant diseases, including breast, prostate, gastric and pancreatic cancers. AIB1 was initially implicated in hormone-dependent breast cancer, where increasing levels of AIB1 mRNA and protein were detected in some of these specimens and the overexpression of AIB1 in mice led to an increased incidence of tumors. More recent studies revealed that AIB1 also affects the growth of hormone-independent breast cancer via signaling pathways such as those of E2F1, IGF-I, EGF and PI3K/Akt/ mTOR. The pleiotropic effect of AIB1 and the roles it plays in both normal development and cancer have presented a great challenge to formulating an effective therapeutic strategy for breast cancer. In this review, we highlight the significant progress made with the recent findings and present an overview of the current understanding of the influence of AIB1 on breast cancer via hormone-dependent and -independent signaling pathways.
\end{abstract}

\section{Contents}

1. Introduction

2. Overview of AIB1 structure and function

3. Implication of AIB1 in breast cancer

4. Conclusion

Correspondence to: Professor Huijian Wu, College of Life Science and Biotechnology, Dalian University of Technology, 2 Ling Gong Road, Dalian, Liaoning 116024, P.R. China

Email:wuhj@dlut.edu.cn

Key words: breast cancer, AIB1, nuclear receptors, hormonedependent signaling

\section{Introduction}

Amplified in breast cancer 1 (AIB1), also known as steroid receptor coactivator-3 (SRC-3), nuclear receptor coactivator-3 (NCoA-3), receptor associated coactivator-3 (RAC-3), activator of thyroid hormone and retinoid receptor (ACTR), thyroid hormone receptor activating molecule-1 (TRAM-1) and $\mathrm{p} 300 / \mathrm{CBP}$ interacting protein $(\mathrm{p} / \mathrm{CIP})$ is a member of the p160 nuclear receptor coactivator family (1). Other members of this family include SRC-1 and SRC-2. The AIB1 gene is located on chromosome 20q12-12, and it was first identified in human breast cancer cells, where approximately $10 \%$ of these cells revealed amplification of the gene and $64 \%$ revealed overexpression of the protein (2). AIB1 was later considered as an oncogene since overexpression of AIB1 in mice led to the spontaneous development of malignant mammary tumors (3), whereas AIB1 ${ }^{-/-}$mice were resistant to chemical carcinogen-induced mammary tumorigenesis $(4,5)$. However, AIB1 also acts as a tumor suppressor since deletion of the AIB1 gene in B-cell lymphoma mice led to the development of B-cell lymphomas (6). Furthermore, results from cell culture systems and targeted gene disruption experiments in mice have demonstrated that AIB1 also plays an essential role in the female reproductive function, puberty, cytokine signaling and vasoprotection (7). The correlation between AIB1 and cancer has been widely investigated since it was shown to be amplified in breast cancer. Initially, AIB1 was thought to promote cancer development through hormone-dependent pathways since it acts as a transcriptional coactivator for nuclear receptors in estrogen receptor (ER)-positive breast cancer. However, various non-nuclear receptor transcription factors, such as E2F1, p53 and NF-kB were found to be coactivated by AIB1, which provides supporting evidence that AIB1 also influences the progress of cancer cells through hormone-independent pathways (8-10). Over the past decade, numerous reviews focusing on the function of AIB1 and its role in cancer have been published (11-19). The focus of this review is to highlight the important progress made with recent findings and to present an overview of the current understanding of the signaling pathways through which the influence of AIB1 leads to the development and progression of breast cancer.

\section{Overview of AIB1 structure and function}

Structural domains of AIB1 and its functions. AIB1 is approximately $160 \mathrm{kDa}$ in size and its structure is conserved across 
different species. The structure of AIB1 consists of a central nuclear receptor interaction domain (NID), an N-terminal basic helix-loop-helix/Per-ARNT-Sim (bHLH/PAS) domain and two activation domains, known as AD1 and AD2, located in the C-terminal region (Fig. 1). In addition, it also contains a serine/threonine-rich domain in the N-terminus, a glutamine (Q)-rich domain, and a histone acetyltransferase (HAT) domain in the $\mathrm{C}$-terminus. The relatively conserved NID domain mainly mediates direct interaction between AIB1 and nuclear receptors, such as ER and androgen receptor (AR) through ligand-dependent pathways. Analysis of the NID sequence has revealed three conserved LXXLL motifs (where $\mathrm{L}$ is leucine and $\mathrm{X}$ is any amino acid) that act as a nuclear receptor box (20). These three LXXLL motifs form an amphipathic $\alpha$-helix in the secondary structure, which then allows the conserved leucines to form a hydrophobic surface that mediates the binding of ligands to the ligand-binding domain of nuclear receptors (13).

The bHLH/PAS domain of AIB1 is conserved in the SRC family with a sequence similarity of approximately $60 \%$. This domain mediates protein-protein interactions that result in the recruitment of other coactivators. The AD1 domain, also named CBP-interaction domain (CID), is involved in direct interaction with the general transcriptional cointegrators, CBP/p300 and PCAF, without interacting with nuclear receptors (21). The AD1 domain also contains three LXXLL/LXXLL-like motifs, which are crucial in promoting the interaction between AIB1 and p300 (22,23). The AD2 domain is mainly responsible for the interaction with histone methyltransferases, including coactivator-associated arginine methyltransferase-1 (CARM1) and protein arginine methyltransferase-1 (PRMT1) (24-26). The HAT activity of the C-terminal domain of AIB1 is weaker than that of $\mathrm{CBP} / \mathrm{p} 300$ and PCAF, and its importance in AIB1 transcriptional activation has yet to be clarified (27-29). The structure and function of AIB1 has previously been extensively reviewed $(11,17)$.

Importance of post-translational modification. Certain serines and threonines in the serine/threonine-rich domain are also sites of phosphorylation. In vitro phosphorylation of AIB1 converts it into a potent transcriptional activator, thereby modifying its oncogenic potential and leading to differential gene expression (30). Phosphorylation of tyrosine residue (Y1357) in the AD2 domain by AbI kinase is required for its activity in cancer cells (31). Dephosphorylation of AIB1 by phosphatases has been shown to be critical for regulating its function and preventing its proteasome-dependent turnover (32), and phosphorylation by atypical protein kinase $\mathrm{C}$ (aPKC), which is frequently overexpressed in cancers, specifically stabilizes AIB1 in an ER-dependent manner through coordinating the inhibition of both ubiquitin-dependent and ubiquitin-independent degradations (33). The turnover of activated AIB1 during tumorigenesis has recently been shown to be mediated by speckle-type POZ protein (SPOP), which is a cullin 3-based ubiquitin ligase (34). A high percentage of loss of heterozyogisty at the SPOP locus was found in breast cancers, and restoration of its expression resulted in the suppression of AIB1-mediated oncogenic signaling and tumorigenesis.

Our previous study demonstrated that phosphorylation of AIB1 is accompanied by a loss in sumoylation and an

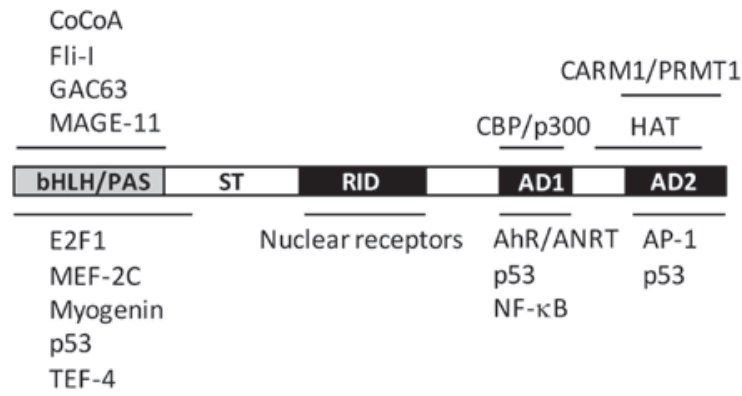

Figure 1. Structural and functional domains of human AIB1. Letters within the bar indicate structural domains. Proteins that are known to interact with AIB1 are shown above and below the lines at the corresponding domains with which they interact. Only representatives of AIB1-interacting proteins are shown. For more examples of AIBI-interacting proteins, see reference 15. bHLH/PAS, basic helix-loop-helix/Per-ARNT-Sim; ST, serine/threonine; RID, receptor interaction domain; AD, activation domain; HAT, histone acetyltransferase domain; CARM1, coactivator-associated arginine methyltransferase-1; CBP/p300, CREB-binding protein/E1 A binding-protein; PRMT1, protein arginine methyltransferase-1.

increase in its transactivation, while dephosphorylation is accompanied by a concomitant increase in sumoylation and reduced transactivation (35). We have recently reported that sumoylation of AIB1 requires the SUMO E3 PIAS1, which coprecipitated with AIB1 in extract prepared from MCF-7 cells, and that overexpression of PIAS1 and AIB1 in MCF-7 cells led to increased sumoylation of AIB1, resulting in repression of its transcriptional activity (36). PIAS1 also increased the stability of AIB1 and attenuated its interaction with ER $\alpha$. These findings suggest that PIAS1 may play a crucial role in the regulation of AIB1 transcriptional activity and its interaction with accessory proteins through sumoylation.

As an ER coactivator, AIB1 regulates ER transcriptional activity through recruitment of the histone acetyltransferases CBP/p300 and PCAF. Acetylation of histones could modify chromatin structure and facilitate ER to bind at the promoters of downstream target genes, leading to enhanced expression of cancer genes. Through sequencing and mapping of genomic DNA fragments obtained by AIB1 ChIP assays, Labhart et al (37) identified 18 putative AIB1 target genes based on their strong AIB1-binding sites, and demonstrated ER $\alpha$ binding with all of these genes. AIB1 also promotes certain transcription factors to interact with other transcription cofactors and this process is regulated by post-translational modifications, including methylation, sumoylation, phosphorylation and acetylation (38). The transcriptional complex of AIB1 in hormone-induced gene expression mediated by the nuclear receptor is shown in Fig. 2.

\section{Implication of AIB1 in breast cancer}

AIB1 and hormone-dependent breast cancer. The AIB1 gene is amplified in approximately 5-10\% of human breast cancers and is overexpressed at both the mRNA (as high as 60\%) and protein levels in approximately $30 \%$ of breast cancers $(2,39-43)$. Further study has revealed that overexpression of AIB1 is correlated with tumor recurrence and survival (44). Increases in AIB1 transcript levels in human breast tumors may also occur by mechanisms 


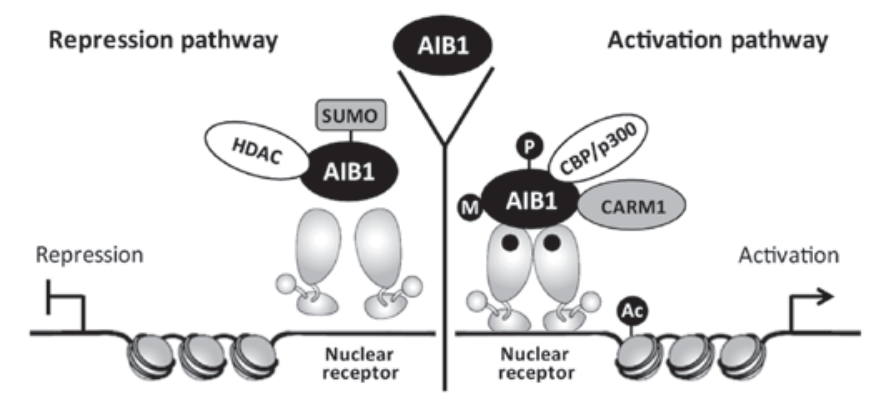

Figure 2. Model depicting the transcriptional complex of AIB1 in steroid hormone-induced gene expression. Black dots within the nuclear receptor represent hormones. AIB1, amplified in breast cancer 1; CARM1, coactivator-associated arginine methyltransferase-1; HDAC, histone deacetylase; Ac, acetylation; M, methylation; $\mathrm{P}$, phosphorylation.

other than gene amplification, such as overexpression of AIB1 mRNA resulting from a loss of ER expression in breast tumor samples (45). A recent study investigating the prognostic significance of AIB1 and its correlation with various steroid hormone receptors (ER, PR, AR, DAX-1 and HER2) shows that for patients suffering from ER-negative breast cancers, strong AIB1 protein expression is correlated with poorer overall survival (46). Besides breast cancer, amplification of AIB1 has also been detected in many other hormone-sensitive tumors, including prostate and ovarian cancers $(2,47)$.

As a member of the steroid receptor coactivator family, AIB1 is essential for the transcriptional activity of certain nuclear receptors (including ER $\alpha$ ), which control processes important for development, homeostasis and reproduction (48). AIB1 is considered to play significant roles in ER-positive breast cancers. The level of ER in breast cancer is considered to be an important marker for most breast cancer therapy and prognosis. As a coactivator for ER, AIB1 is thought to influence the growth of hormone-dependent breast cancer through mediating the effects of estrogen on ER $\alpha$-dependent gene expression $(2,41)$, and this serves as a mechanism by which AIB1 modulates the growth of hormone-dependent breast cancer. This mechanistic model is supported by a study showing that depletion of AIB1 may inhibit estrogen-stimulated cell proliferation and survival in ER-positive MCF-7 human breast cancer cells, leading to a decrease in growth of MCF-7 xenografts in mice $(49,50)$. However, not all ER $\alpha$-positive breast cancers are associated with higher levels of AIB1 mRNA, as ER $\alpha$-negative breast cancer has also been found to be associated with high levels of AIB1 mRNA (14). Discrepancy among these studies is thought to be caused by differences in the role and regulation of AIB1 and the hormone receptors at different stages of breast cancer. A recent study has uncovered evidence of an association between silencing mediator of retinoic acid and thyroid hormone receptor (SMRT) with AIB1 in the regulation of ER-dependent gene expression, such as the expression of progesterone receptor and cyclin D1 genes (51). SMRT is able to bind directly to AIB1 independently of ER, and this complex then promotes the subsequent E2-dependent binding of AIB1 to ER, demonstrating that SMRT promotes ER- and AIB1-dependent gene expression in breast cancer.
The correlation between AIB1 and breast cancer has also been investigated using several AIB1-depleted mouse models. In mice harbouring the mouse mammary tumor virus/v-Ha-ras (ras) transgene, breast tumor incidence was notably reduced in intact $\mathrm{AIB1}^{-/-}$-ras virgin mice compared to complete inhibition in ovariectomized $\mathrm{AIB}^{-/-}$-ras mice (4). Furthermore, the level of IGF-1 expression and insulin receptor substrate (IRS)-1 and -2 proteins in the mammary glands and tumors of these mice were significantly reduced, which contributed in part to the suppression of mammary tumorigenesis and metastasis. In another model, mice lacking AIB1 were shown to be resistant to chemical carcinogen-induced mammary tumorigenesis (5). In a different mouse model, deletion of one allele of AIB1 in MMTV-Neu mice was found to significantly delay Neu-induced mammary tumor development, demonstrating that AIB1 is required for $\mathrm{Neu}$ (ErbB2/HER2) activation, signaling and mammary tumorigenesis (52). Although these animal models have provided important data on the involvement of AIB1 in breast cancer by allowing the disease to be simulated or recreated under controlled conditions, they still do not represent the real condition of the disease in the case of humans, and at best, should only be regarded as a mimic. Thus, what have been learned from animal models may not necessarily be completely applicable to humans.

AIB1 also appears to play a significant role in the resistance of breast cancer to anti-estrogen therapy. Over the past few decades, tamoxifen has been the standard endocrine therapy for treating ER-positive breast cancer. Tamoxifen is a non-steroidal estrogen receptor antagonist (but also exhibits agonist activity) and functions by competitively blocking the binding of estrogen to ER, thereby inhibiting estrogen-mediated gene expression and estrogen-dependent cell growth (53). However, the use of tamoxifen has gradually led to the emergence of tamoxifen resistance in breast cancer. The involvement of AIB1 in tamoxifen resistance has been demonstrated in breast cancer patients, whereby disease-free and overall survival is correlated with high expression of AIB1. There is also evidence linking the expression of AIB1 protein and breast tumor recurrence in ErbB2-positive breast tumors, and knockdown of AIB1 in tamoxifen-resistant, ErbB2-positive breast cancer cell line BT474 restored its sensitivity to tamoxifen (54). These results appear to indicate that the expression of AIB1 is associated with resistance to tamoxifen for ER-positive breast cancer patients undergoing tamoxifen treatment. The underlying mechanism for tamoxifen resistance has been further clarified by data obtained from an in vivo breast tumor model, which showed that tamoxifen resistance in ER-positive breast cancer is also mediated by EGFR/HER2, even though ER genomic function is suppressed by tamoxifen (55). In a recent study, Karmakar et al (56) evaluated the role of AIB1 and two other SRC coactivators in the growth of the estrogen-independent and tamoxifen-resistant breast cancer cell line LCC2 and found that these coactivators exert a mixture of ligand-dependent and ligand-independent effects on the regulation of cell growth and apoptosis. Furthermore, these authors demonstrated that growth of LCC2 cells is controlled by AIB1 and SCR-2, largely through the control of basal cell growth, and suggested that targeting growth inhibition via SRC-2 and AIB1 may offer a more effective way to inhibit the growth 
of tamoxifen-resistant breast cancer. Resistance to tamoxifen is now being viewed as a result of crosstalk between ER and growth factor signaling pathways $(57,58)$. AIB1 is considered to play a positive role in tamoxifen resistance since overexpression of AIB1 alone has been shown to increase the agonist properties of tamoxifen in breast cancer cell lines (59). Taken together, these existing findings support the notion that tamoxifen resistance is a product of multiple mechanisms, and that AIB1 appears to play an important role; however, further investigation is required to provide a more definitive understanding of its underlying mechanism.

A more recent study concerned with the global characterization of the transcriptional impact of AIB1 has shed more light on the scope of AIB1 target genes and provides a molecular framework for AIB1 in interpreting estrogen signaling (60). This study, which combines genome-wide mapping of AIB1 affinity sites in MCF-7 cells with RNA expression signatures and a proteomic approach, is so far the most sophisticated study to identify the transcriptional regulatory network of AIB1. It also opens up new areas for exploring the hormone-dependent signaling of breast cancer afforded by AIB1.

AIB1 and hormone-independent breast cancer. Although AIB1 levels have been shown to be a limiting factor for ER-positive breast cancer growth through hormone-dependent pathways, substantial evidence has suggested that AIB1 stimulates the growth of cancer cells through hormone-independent pathways. For example, in a recent study, Torres-Arzayus et al (61) addressed the role of estrogen and ER $\alpha$ in AIB1-mediated tumor formation and showed that AIB1 transgenic mice that had their ovaries removed at the prepubertal stage to block estrogen production did not develop any invasive mammary gland tumors. However, these animals showed higher incidence of pituitary, lung, skin and bone tumors than their non-ovariectomized counterparts. They also crossed AIB1 transgenic mice with ER $\alpha$-null mutant mice and found that mice lacking ER $\alpha$ were unable to respond to estrogen through this receptor. At the same time, these animals showed no signs of mammary tumors but developed tumors in the lung, skin, and pituitary gland with the same incidence as their ER $\alpha$-positive AIB1 transgenic counterparts. The authors concluded from these findings that depending on the organ or tissue affected, AIB1 causes tumor formation by estrogen-dependent and estrogen-independent mechanisms, and that AIB1 exerts its oncogenic activities in cell signaling that are independent of its function as an ER coactivator. Other studies have also indicated the involvement of AIB1 in breast cancer through certain hormone-independent pathways, including E2F1, IGF-I and EGF signaling (Fig. 3) (7,62).

Overexpression of AIB1 has been found to increase cell proliferation even in the presence of nuclear receptor antagonist (9). More convincingly, the overexpression of AIB1 promotes the growth of hormone-independent cancer cells through enhancing the transcription of E2F target genes, which are mostly G1/S cycle transition-related proteins, such as E2F1, cyclin E and cyclin-dependent kinase 2 (Cdk2) (9). AIB1 interacts with the transcriptional factor E2F1, and this then results in the recruitment of AIB1 to the E2F-binding sites

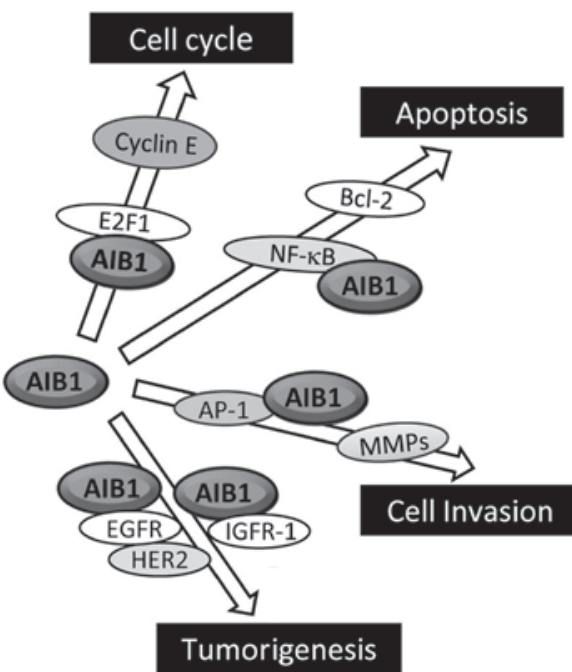

Figure 3. Hormone-independent pathways through which AIB1 may participate in the development of cancer. AIB1, amplified in breast cancer 1 .

on the target gene promoters, eventually leading to activation of these E2F-dependent downstream genes. Notably, AIB1 promotes its own transcription with $\mathrm{E} 2 \mathrm{~F} 1$, and this positive feedback regulatory loop is thought to enhance the influence AIB1 exerts on cell cycle control. Overexpression of AIB1 has also been found to correlate with high levels of $\mathrm{p} 53$ proteins in invasive breast cancer cells (45).

The association of AIB1 with the regulation of IGF-I signaling in cancer is supported by the finding that AIB1 knockout downregulates the expression levels of both IGF-I mRNA and protein, whereas overexpression of AIB1 has the opposite effect (63). In addition, AIB1 may also regulate the expression of many IGF-I signaling components, including IGF-I receptor $\beta$ (IGF-IR $\beta$ ), IRS-1 and IRS-2 in vitro and in vivo. Although the mechanism as to how AIB1 modulates IGF-I signaling in cancers is not clear, it has been reported that AIB1 binds to the transcription factor AP-1 and promotes AP-1-mediated transcription of IGF-I and IRS-1 (64). In addition, AIB1 knockout mice have an impaired ability in their response to IGF-I stimulation and are unresponsive to IGF-I-induced DNA synthesis. This may in part be explained by the result from the study conducted by Liao et al (65), which shows that $\mathrm{AIB1}^{-/}$mice have lower levels of circulating IGF-I compared to wild-type mice, a consequence of rapid IGF-I degradation rather than lower expression. The rapid IGF-I degradation is caused by a lack of expression of IGF-binding protein 3 (IGFBP-3), which is induced by vitamin $\mathrm{D}$ through a vitamin $\mathrm{D}$ receptor (VDR). These results point to a role of AIB1 in maintaining the circulating level of IGF-I through increasing VDR-regulated IGFBP-3 expression. The PI3K/Akt/mTOR pathway is also associated with AIB1-mediated tumorigenesis, since it was shown that mammary hyperplasia and hypertrophy induced in mice via overexpression of AIB1 can be prevented by inhibition of mTOR with the rapamycin analog RAD001 (66). RAD001 also inhibits the growth of AIB1-induced tumor xenografts in mice. 
EGF signaling is known to play a crucial role in the initiation and progression of breast cancer (67). The influence of AIB1 on breast cancer via EGF signaling is supported by a study showing that AIB1 knockdown by siRNA reduced EGF-mediated phosphorylation of EGFR and HER-2, leading to inhibition of the activation of EGF signaling in lung, pancreatic and breast cancer cells and confirming that AIB1 regulates EGF signaling to promote the proliferation of cancer cells (68). Taken together, these studies indicate that the role of AIB1 extends beyond the actions of steroid hormone receptors in cancer cells.

The role of AIB1 in cancer progression and metastasis. AIB1 plays a significant role in mammary tumor progression and metastasis through mediating tumor cell motility and invasion $(18,43,69)$. AIB1 $^{-/}$mice harboring the mouse mammary tumor virus-polomavirus middle $\mathrm{T}$ (PyMT) transgene or $\mathrm{AIB1}^{-/} / \mathrm{PyMT}$ human tumor cells were found to have reduced expression of MMP2 and MMP9, resulting in lower cell-invasive and metastatic capabilities (43). AIB1 acts as a PEA3 coactivator by forming complexes with PEA3 on MMP2 and MMP9 promoters to enhance their expression in both mouse and human breast cancer cells. Furthermore, a AIB1 splice isoform lacking the N-terminal bHLH domain (due to the deletion of exon 4) that is overexpressed in breast cancer cells and tumors has also been shown to play critical roles in promoting cancer cell proliferation, invasion and metastasis through acting as a missing adaptor protein that bridges the interaction between EGFR and FAK (a non-receptor tyrosine kinase) following EGF stimulation (69).

Influence of AIBI on tumor suppressor gene and cancer. A hallmark of cancer is often an improper balance between cell proliferation and apoptosis. Oncogene activation coupled with loss of tumor suppressor function would enable the cell to escape senescence and apoptosis, thereby providing an advantage for tumorigenesis. A number of studies have demonstrated the involvement of AIB1 in apoptosis. For example, knockdown of AIB1 by siRNA in human chronic myeloid leukemia K562 cells reduces activation of $\mathrm{NF}-\kappa \mathrm{B}$ signaling, ultimately leading to apoptosis (70), while overexpression of AIB1 in human embryonic kidney 293 (HEK293) cells has the reverse effect (71). A study by Ferragud et al (72) revealed that AIB1 acts as a negative regulator for DROI, a tumor suppressor gene that was first identified as upregulated in brown adipose tissue of mice deficient in bombesin receptor subtype-3 (73). The function of DROI as a tumor suppressor gene was later demonstrated when its expression was shown to be highly reduced in colon and pancreatic cancers (74). Further investigation revealed that DROI plays an important role in adipogenesis through downregulating Wnt/ $\beta$-catenin signaling and inducing $\mathrm{C} / \mathrm{EBP} \alpha$ and PPAR $\gamma$ (75). The expression of DROI was significantly reduced in mouse mammary epithelial cells or human primary cultures overexpressing AIB1 (72). Furthermore, DROI expression levels decreased in MCF-7 cells treated with estrogen but increased when treated with tamoxifen. Another study identified the tumor suppressor 53BP1 (a DNA-damaging response protein) as a novel AIB1-interacting protein, and through chromatin immunoprecipitation (ChIP) and siRNA knockdown experiments, AIB1 and 53BP1 were shown to co-occupy the same region of the breast cancer type 1 susceptibility protein (BRCA1) promoter, and both proteins were required for BRCA1 expression in HeLa cells (76). There was no evidence to indicate that AIB1 plays a direct role in DNA damage response; however, these authors concluded that the association between 53BP1 and AIB1 may modulate the transcriptional response of the $B R C A 1$ gene and possibly regulate the activity of a subset of target genes involved in DNA repair. Taken together, these results demonstrate yet another mechanistic feature of AIB1 in cancer development, one that occurs via its suppression of tumor suppressor genes.

\section{Conclusion}

For the past few decades, endocrine therapy has been the most effective treatment for women with ER-positive breast cancer. However, the emergence of resistance to endocrine therapy has prompted the search for a different strategy, which involves targeting both ER and growth factor receptor signaling (77). Therapeutic approaches that simultaneously target ER and components of growth factor signaling, such as EGFR, HER2 and PI3K, have had some success in the preclinical setting. However, extensive further study is required to take this approach beyond the preclinical setting. As far as the role of AIB1 in breast cancer is concerned, given the pleiotropic effect of this coactivator and the complexity of the signaling network that it participates in and regulates, it becomes a great challenge to conceive of a long-term therapeutic strategy that effectively eliminates the cancer and prevents recurrence of the disease. Post-translational modification of AIB1 in the form of phosphorylation and its relevance to cancer is still not fully elucidated, and there has been suggestion that if the phosphoforms of AIB1 are important in human malignant disease then targeting these phosphoforms of AIB1 may be a useful therapeutic approach (17). Interrupting nuclear receptor coactivator interactions has been suggested to be beneficial in treating nuclear receptor-mediated diseases, including breast cancer (19). However, specifically targeting AIB1 or any of its associated transcription factors, coactivators or accessory proteins is unlikely to be effective, since such a measure is likely to upset the overall cellular reaction network in the long term, resulting in potential side effects. Nevertheless, future research should focus on gaining more insight into the mechanistic functions and regulations of AIB1, particularly those concerned with its dysfunctions that ultimately trigger the onset of cancers. Studies on the post-translational modifications (including sumoylation, which still requires extensive research) that govern the regulation and turnover of the AIB1 protein with respect to its modulation of cancer development and progression are also important and relevant to the overall therapeutic strategy for combating breast cancers mediated by this transcriptional coactivator.

\section{Acknowledgements}

This study was supported by a grant (30771221 to H.W.) from the National Natural Science Foundation of China and a grant (973 Program 2011CB504201 to H.W.) from the Ministry of Science and Technology of China. 


\section{References}

1. Xu J and Li Q: Review of the in vivo functions of the p160 steroid receptor coactivator family. Mol Endocrinol 17: 1681-1692, 2003 .

2. Anzick SL, Kononen J, Walker RL, Azorsa DO, Tanner MM, Guan XY, Sauter G, Kallioniemi OP, Trent JM and Meltzer PS AIB1, a steroid receptor coactivator amplified in breast and ovarian cancer. Science 277: 965-968, 1997.

3. Torres-Arzayus MI, Font de Mora J, Yuan J, Vazquez F, Bronson R, Rue M, Sellers WR and Brown M: High tumor incidence and activation of the PI3K/AKT pathway in transgenic mice define AIB1 as an oncogene. Cancer Cell 6 : 263-274, 2004

4. Kuang SQ, Liao L, Zhang H, Lee AV, O'Malley BW and Xu J: AIB1/SRC-3 deficiency affects insulin-like growth factor 1 signaling pathway and suppresses v-Ha-ras-induced breast cancer initiation and progression in mice. Cancer Res 64: 1875-1885, 2004.

5. Kuang SQ, Liao L, Wang S, Medina D, O'Malley BW and Xu J: Mice lacking the amplified in breast cancer $1 /$ steroid receptor coactivator-3 are resistant to chemical carcinogen-induced mammary tumorigenesis. Cancer Res 65: 7993-8002, 2005.

6. Coste A, Antal MC, Chan S, Kastner P, Mark M, O'Malley BW and Auwerx J: Absence of the steroid receptor coactivator-3 induces B-cell lymphoma. EMBO J 25: 2453-2464, 2006.

7. Ma G, Ren Y, Wang K and He J: SRC-3 has a role in cancer other than as a nuclear receptor coactivator. Int J Biol Sci 7: 664-672, 2011.

8. Werbajh S, Nojek I, Lanz R and Costas MA: RAC-3 is a NF-kappa B coactivator. FEBS Lett 485: 195-199, 2000.

9. Louie MC, Zou JX, Rabinovich A and Chen HW: ACTR/AIB1 functions as an E2F1 coactivator to promote breast cancer cell proliferation and antiestrogen resistance. Mol Cell Biol 24: 5157-5171, 2004.

10. Yamashita $\mathrm{H}$, Takahashi $\mathrm{S}$, Ito $\mathrm{Y}$, Yamashita $\mathrm{T}$, Ando $\mathrm{Y}$, Toyama T, Sugiura H, Yoshimoto N, Kobayashi S, Fujii Y and Iwase $\mathrm{H}$ : Predictors of response to exemestane as primary endocrine therapy in estrogen receptor-positive breast cancer. Cancer Sci 100: 2028-2033, 2009

11. Liao L, Kuang SQ, Yuan Y, Gonzalez SM, O'Malley BW and $\mathrm{Xu} \mathrm{J}$ : Molecular structure and biological function of the cancer-amplified nuclear receptor coactivator SRC-3/AIB1. J Steroid Biochem Mol Bio 83: 3-14, 2002.

12. Yan J, Tsai SY and Tsai MJ: SRC-3/AIB1: transcriptional coactivator in oncogenesis. Acta Pharmacol Sin 27: 387-394, 2006.

13. Amazit L, Pasini L, Szafran AT, Berno V, Wu RC, Mielke M, Jones ED, Mancini MG, Hinojos CA, O'Malley BW and Mancini MA: Regulation of SRC-3 intercompartmental dynamics by estrogen receptor and phosphorylation. Mol Cell Biol 27: 6913-6932, 2007.

14. Lahusen T, Henke RT, Kagan BL, Wellstein A and Riegel AT: The role and regulation of the nuclear receptor co-activator AIB in breast cancer. Breast Cancer Res Treat 116: 225-237, 2009.

15. Xu J, Wu RC and O'Malley BW: Normal and cancer-related functions of the p160 steroid receptor co-activator (SRC) family. Nat Rev Cancer 9: 615-630, 2009.

16. Gojis O, Rudraraju B, Alifrangis C, Krell J, Libalova P and Palmieri C: The role of steroid receptor coactivator-3 (SRC-3) in human malignant disease. Eur J Surg Oncol 36: 224-229, 2010.

17. Gojis O, Rudraraju B, Gudi M,Hogben K, Sousha S, Coombes RC, Cleator S and Palmieri C: The role of SRC-3 in human breast cancer. Nat Rev Clin Oncol 7: 83-89, 2010.

18. Lydon JP and O'Malley BW: Minireview: steroid receptor coactivator-3: a multifarious coregulator in mammary gland metastasis. Endocrinology 152: 19-25, 2011.

19. Johnson AB and O'Malley BW: Steroid receptor coactivators 1,2 , and 3: critical regulators of nuclear receptor activity and steroid receptor modulator (SRM)-based cancer therapy. Mol Cel Endocrinol 348: 430-439, 2012.

20. Savkur RS and Burris TP: The coactivator LXXLL nuclear receptor recognition motif. J Pept Res 63: 207-212, 2004.

21. Chen H, Lin RJ, Schilz RL, Chakravarti D, Nash A, Nagy L, Privalsky ML, Nakatani Y and Evans RM: Nuclear receptor coactivator ACTR is a novel histone acetyltransferase and forms a multimeric activation complex with $\mathrm{p} / \mathrm{CAF}$ and $\mathrm{CBP} / 300$ Cell 90: 569-580, 1997.
22. Voegel JJ, Heine MJ, Tini M, Vivat V, Chambon $\mathrm{P}$ and Gronemeyer $\mathrm{H}$ : The coactivator TIF2 contains three nuclear receptor-binding motifs and mediates transactivation through CBP binding-dependent and -independent pathways. EMBO J 17 : 507-519, 1998.

23. Li J, O'Malley BW and Wong J: p300 requires its histone acetyltransferase activity and SRC-1 interaction domain to facilitate thyroid hormone receptor activation in chromatin. Mol Cell Biol 20: 2031-2042, 2000

24. Qi C, Chang J, Zhu Y, Yeldandi AV, Rao SM and Zhu YJ: Identification of protein arginine methyltransferase 2 as a coactivator for estrogen receptor alpha. J Biol Chem 277: 28624-28630, 2002

25. Teyssier C, Chen D and Stallcup MR: Requirement for multiple domains of the protein arginine methyltransferase CARM1 in its transcriptional coactivator function. J Biol Chem 277: 46066-46072, 2002.

26. Lee DY, Teyssier C, Strahl BD and Stallcup MR: Role of protein methylation in regulation of transcription. Endocr Rev 26 147-170, 2005.

27. Spencer TE, Jenster G, Burcin MM, All is CD,Zhou J, Mizzen CA, McKenna NJ, Onate SA, Tsai SY, Tsai MJ and O'Malley BW: Steroid receptor coactivator-1 is a histone acetyl transferase. Nature 389: 194-198, 1997.

28. Chen D, Ma H, Hong H, Koh SS, Huang SM, Schurter BT, Aswad DW and Stallcup MR: Regulation of transcription by a protein methyltransferase. Science 284: 2174-2177, 1999.

29. Koh SS, Chen D, Lee YH and Stallcup MR: Synergistic enhancement of nuclear receptor function by p160 coactivators and two coactivators with protein methyltransferase activities. J Biol Chem 276: 1089-1098, 2001

30. Wu RC, Smith CL and O'Malley BW: Transcriptional regulation by steroid receptor coactivator phosphorylation. Endocr Rev 26 393-399, 2005

31. Oh AS, Lahusen JT, Chien CD, Fereshteh MP, Zhang X, Dakshanamurthy S, Xu J, Kagan BL, Wellstein A and Riegel AT: Tyrosine phosphorylation of the nuclear receptor coactivator AIB1/SRC-3 is enhanced by Abl kinase and is required for its activity in cancer cells. Mol Cell Biol 28: 6580-6593, 2008.

32. Li C, Liang YY, Feng XH, Tsai SY, Tsai MJ and O'Malley BW: Essential phosphatases and a phospho-degron are critical for regulation of SRC-3/AIB1 coactivator function and turnover. Mol Cell 31: 835-849, 2008.

33. Yi P, Feng Q, Amazit L, Lonard DM, Tsai SY, Tsai MJ and O'Malley BW: Atypical protein kinase $\mathrm{C}$ regulates dual pathways for degradation of the oncogenic coactivator SRC-3/AIB1. Mol Cell 29: 465-476, 2008

34. Li C, Ao J, Fu J, Lee DF, Xu J, Lonard D and O'Malley BW: Tumor-suppressor role for the SPOP ubiquitin ligase in signal-dependent proteolysis of the oncogenic co-activator SRC-3/AIB1. Oncogene 30: 4350-4364, 2011.

35. Wu H, Sun L, Zhang Y, Chen Y, Shi B, Li R, Wang Y, Liang J, Fan D, Wu G, et al: Coordinated regulation of AIB1 transcriptional activity by sumolylation and phosphorylation. J Biol Chem 281: 21848-21856, 2006.

36. Li S, Yang C, Hong Y, Bi H, Zhao F, Liu Y, Ao X, Pang P, Xing X, Chang AK, et al: The transcriptional activity of co-activator AIB1 is regulated by the SUMO E3 Ligase PIAS1. Biol Cell 104: 287-296, 2012

37. Labhart P, Karmakar S, Salicru EM, Egan BS, Alexiadis V, O'Malley BW and Smith CL: Identification of target genes in breast cancer cells directly regulated by the SRC-3/AIB1 coactivator. Proc Natl Acad Sci USA 102: 1339-1344, 2005.

38. Li S and Shang Y: Regulation of SRC family coactivators by post-translational modifications. Cell Signal 19: 1101-1112, 2007.

39. Bautista S, Vallès H, Walker RL, Anzick S, Zeillinger R, Meltzer $\mathrm{P}$ and Theillet $\mathrm{C}$ : In breast cancer, amplification of the steroid receptor coactivator gene AIB1 is correlated with estrogen and progesterone receptor positivity. Clin Cancer Res 4: 2925-2929, 1998

40. Glaeser M, Floetotto T, Hanstein B, Beckmann MW and Niederacher D: Gene amplification and expression of the steroid receptor coactivator SRC3 (AIB1) in sporadic breast and endometrial carcinomas. Horm Metab Res 33: 121-126, 2001.

41. List HJ, Reiter R, Singh B, Wellstein A and Riegel AT: Expression of the nuclear coactivator AIB1 in normal and malignant breast tissue. Breast Cancer Res Treat 68: 21-28, 2001 . 
42. Zhao C, Yasui K, Lee CJ, Kurioka H, Hosokawa Y, Oka T and Inazawa J: Elevated expression levels of NCOA3, TOP1, and TFAP2C in breast tumors as predictors of poor prognosis. Cancer 98: 18-23, 2003.

43. Qin L, Liao L, Redmond A, Young L, Yuan Y, Chen H, O'Malley BW and Xu J: The AIB1 oncogene promotes breast cancer metastasis by activation of PEA3-mediated matrix metallopteinase 2 (MMP2) and MMP9 expression. Mol Cell Biol 28 5937-5950, 2008

44. Kirkegaard T, McGlynn LM, Campbell FM, Müller S, Tovey SM Dunne B, Nielsen KV, Cooke TG and Bartlett JM: Amplified in breast cancer 1 in human epidermal growth factor receptorpositive tumors of tamoxifen-treated breast cancer patients. Clin Cancer Res 13: 1405-1411, 2007.

45. Bouras T, Southey MC and Venter DJ: Overexpression of the steroid receptor coactivator AIB1 in breast cancer correlates with the absence of estrogen and progesterone receptors and positivity for $\mathrm{p} 53$ and HER2/neu. Cancer Res 61: 903-907, 2001

46. Lee K, Lee A, Song BJ and Kang CS: Expression of AIB1 protein as a prognostic factor in breast cancer. World J Sur Oncol 9: 139, 2011.

47. Gnanapragasam VJ, Leung HY, Pulimood AS, Neal DE and Robson CN: Expression of RAC 3, a steroid hormone receptor co-activator in prostate cancer. Br J Cancer 85: 1928-1936, 2001

48. Barkhem T, Nilsson S and Gustafsson JA: Molecular mechanisms, physiological consequences and pharmacological implications of estrogen receptor action. Am J Pharmacogenomics 4: 19-28, 2004

49. List HJ, Lauritsen KJ, Reiter R, Powers C, Wellstein A and Riegel AT: Ribozyme targeting demonstrates that the nuclear receptor coactivator AIB1 is a rate-limiting factor for estrogen-dependent growth of human MCF-7 breast cancer cells. J Biol Chem 276: 23763-23768, 2001.

50. Karmakar S, Foster EA and Smith CL: Unique roles of p160 coactivators for regulation of breast cancer cell proliferation and estrogen receptor-alpha transcriptional activity. Endocrinology 150: 1588-1596, 2009

51. Karmakar S, Gao T, Pace MC, Oesterreich S and Smith CL: Cooperative activation of cyclin D1 and progesterone receptor gene expression by the SRC-3 coactivator and SMRT corepressor. Mol Endocrinol 24: 1187-1202, 2010.

52. Fereshteh MP, Tilli MT, Kim SE, Xu J, O'Malley BW, Wellstein A, Furth PA and Riegel AT: The nuclear receptor coactivator amplified in breast cancer-1 is required for Neu (ErbB2/HER2) activation, signaling, and mammary tumorigenesis in mice. Cancer Res 68: 3697-3706, 2008.

53. Alkner S, Bendahl PO, Grabau D, Lövgren K, Stål O, Rydén L and Fernö M; Swedish and South-East Swedish Breast Cancer Groups: AIB1 is a predictive factor for tamoxifen response in premenopausal women. Ann Oncol 21: 238-244, 2010

54. Su Q, Hu S, Gao H, Ma R, Yang Q, Pan Z, Wang T and Li F: Role of AIB1 for tamoxifen resistance in estrogen receptor-positive breast cancer cells. Oncology 75: 159-168, 2008.

55. Massarweh S, Osborne CK, Creighton CJ, Qin L, Tsimelzon A, Huang S, Weiss H, Rimawi M and Schiff R: Tamoxifen resistance in breast tumors is driven by growth factor receptor signaling with repression of classic estrogen receptor genomic function. Cancer Res 68: 826-833, 2008.

56. Karmakar S, Foster EA, Blackmore JK and Smith CL: Distinctive functions of p160 steroid receptor coactivators in proliferation of an estrogen-independent, tamoxifen-resistant breast cancer cell line. Endocr Relat Cancer 18: 113-127, 2011.

57. Osborne CK, Shou J, Massarweh S and Schiff R: Crosstalk between estrogen receptor and growth factor receptor pathways as a cause for endocrine therapy resistance in breast cancer. Clin Cancer Res 11: 865s-870s, 2005.

58. Arpino G, Wiechmann L, Osborne CK and Schiff R: Crosstalk between the estrogen receptor and the HER tyrosine kinase receptor family: molecular mechanism and clinical implications for endocrine therapy resistance. Endocr Rev 29: 217-233, 2008.

59. Reiter R, Oh AS, Wellstein A and Riegel AT: Impact of the nuclear receptor coactivator AIB1 isoform AIB1-Delta3 on estrogenic ligands with different intrinsic activity. Oncogene 23 : 403-409, 2004
60. Lanz RB, Bulynko Y, Malovannaya A, Labhart P, Wang L, Li W, Qin J, Harper M and O'Malley BW: Global characterization of transcriptional impact of the SRC-3 coregulator. Mol Endocrinol 24: 859-872, 2010.

61. Torres-Arzayus MI, Zhao J, Bronson R and Brown M: Estrogen-dependent and estrogen-independent mechanisms contribute to AIB1-mediated tumor formation. Cancer Res 70: 4102-4111, 2010.

62. Silva CM and Shupnik MA: Integration of steroid and growth factor pathways in breast cancer: focus on signal transducers and activators of transcription and their potential role in resistance. Mol Endocrinol 21: 1499-1512, 2007.

63. Oh A, List HJ, Reiter R, Mani A, Zhang Y, Gehan E, Wellstein A and Riegel AT: The nuclear receptor coactivator AIB1 mediates insulin-like growth factor I-induced phenotypic changes in human breast cancer cells. Cancer Res 64: 8299-8308, 2004.

64. Yan J, Yu CT, Ozen M, Ittmann M, Tsai SY and Tsai MJ: Steroid receptor coactivator-3 and activator protein-1 coordinately regulate the transcription of components of the insulin-like growth factor/AKT signaling pathway. Cancer Res 66: 11039-11046, 2006.

65. Liao L, Chen X, Wang S, Parlow AF and Xu J: Steroid receptor coactivator 3 maintains circulating insulin-like growth factor (IGF-I) by controlling IGF-binding protein 3 expression. Mol Cell Biol 28: 2460-2469, 2008.

66. Torres-Arzayus MI, Yuan J, DellaGatta JL, Lane H, Kung AL and Brown M: Targeting the AIB1 oncogene through mammalian target of rapamycin inhibition in the mammary gland. Cancer Res 66: 11381-11388, 2006

67. Hardy KM, Booth BW, Hendrix MJ, Salomon DS and Strizzi L: ErbB/EGF signaling and EMT in mammary development and breast cancer. J Mammary Gland Biol Neoplasia 15: 191-199, 2010.

68. Lahusen T, Fereshteh M, Oh A, Wellstein A and Riegel AT: Epidermal growth factor receptor tyrosine phosphorylation and signaling controlled by a nuclear receptor coactivator, amplified in breast cancer 1. Cancer Res 67: 7256-7265, 2007.

69. Long W, Yi P, Amazit L, LaMarca HL, Ashcroft F, Kumar R, Mancini MA, Tsai SY, Tsai MJ and O'Malley BW: SRC-3Delta4 mediates the interaction of EGFR with FAK to promote cell migration. Mol Cell 37: 321-332, 2010.

70. Colo GP, Rosato RR, Grant S and Costas MA: RAC3 down-regulation sensitizes human chronic myeloid leukemia cells to TRAIL-induced apoptosis. FEBS Lett 581: 5075-5081, 2007.

71. Colo GP, Rubio MF, Nojek IM, Werbajh SE, Echeverría PC, Alvarado CV, Nahmod VE, Galigniana MD and Costas MA: The p160 nuclear receptor co-activator RAC3 exerts an anti-apoptotic role through a cytoplasmatic action. Oncogene 27: 2430-2444, 2008.

72. Ferragud J, Avivar-Valderas A, Pla A, De Las Rivas J and de Mora JF: Transcriptional repression of the tumor suppressor DRO1 by AIB1. FEBS Lett 585: 3041-3046, 2011.

73. Aoki K, Sun YJ, Aoki S, Wada K and Wada E: Cloning, expression, and mapping of a gene that is upregulated in adipose tissue of mice deficient in bombesin receptor subtype-3. Biochem Biophys Res Commun 290: 1282-1288, 2002.

74. Bommer GT, Jäger C, Dürr EM, Baehs S, Eichhorst ST, Brabletz T, Hu G, Fröhlich T, Arnold G, Kress DC, et al: DRO1, a gene down-regulated by oncogenes, mediates growth inhibition in colon and pancreatic cancer cells. J Biol Chem 280: 7962-7975, 2005.

75. Tremblay F, Revett T, Huard C, Zhang Y, Tobin JF, Martinez RV and Gimeno RE: Bidirectional modulation of adipogenesis by the secreted protein Ccdc80/DRO1/URB. J Biol Chem 284: 8136-8147, 2009.

76. Corkery D, Thillainadesan G, Coughlan N, Mohan RD, Isovic M, Tini $\mathrm{M}$ and Torchia J: Regulation of the BRCA1 gene by an SRC3/53BP1 complex. BMC Biochem 12: 50, 2011.

77. Osborne CK and Schiff R: Mechanisms of endocrine resistance in breast cancer. Annu Rev Med 62: 233-247, 2011. 